\title{
Gender effects for loss aversion: Yes, no, maybe?
}

\author{
Ranoua Bouchouicha ${ }^{1}$ - Lachlan Deer ${ }^{2}$. Ashraf Galal Eid ${ }^{3}$. Peter McGee . $^{4}$ \\ Daniel Schoch ${ }^{5}$. Hrvoje Stojic ${ }^{6}$. Jolanda Ygosse-Battisti ${ }^{7}$. \\ Ferdinand M. Vieider ${ }^{8}$
}

Published online: 2 December 2019

(C) The Author(s) 2019

\begin{abstract}
Gender effects in risk taking have attracted much attention by economists, and remain debated. Loss aversion - the stylized finding that a given loss carries substantially greater weight than a monetarily equivalent gain-is a fundamental driver of risk aversion. We deploy four definitions of loss aversion commonly used in the literature to investigate gender effects. Even though the definitions only differ in subtle ways, we find women to be more loss averse than men according to one definition, while another definition results in no gender differences, and the remaining two definitions point to women being less loss averse than men. Conceptually, these contradictory effects can be organized by systematic measurement error resulting from model misspecifications relative to the true underlying decision process.
\end{abstract}

Keywords Loss aversion - Gender effects · Risk preferences · Prospect theory

JEL Classifications D03 - D81 · C51

\section{Motivation}

Gender effects in risk taking behaviour are a much-debated topic. The interest in differential risk taking by the sexes can be ascribed to its role as a potential explanation for gender differences in investment behaviour (Sunden and Surette 1998; Dwyer et al. 2002), or for the differential willingness to compete by men and women (Niederle and Vesterlund 2005; Balafoutas and Sutter 2012). There is, however, little agreement on whether women truly have less appetite for risk than men. While some findings indeed suggested that this is the case (see Croson and Gneezy 2009, for a

Ranoua Bouchouicha

r.bouchouicha@ reading.ac.uk

Extended author information available on the last page of the article. 
review), a recent meta-analysis has cast doubt on the universality of gender effects (Filippin and Crosetto 2016).

Loss aversion - the stylized finding that a given loss provides more disutility than a monetarily equivalent gain provides utility (Markowitz 1952; Kahneman and Tversky 1979) - is a central component of risk aversion. Loss aversion has been used to explain a wide variety of empirical phenomena (Benartzi and Thaler 1995; Gneezy and Potters 1997; Schmidt 2003). It is thought to be the driving factor of any risk aversion in small-stake decisions (Rabin and Thaler 2001; Köbberling and Wakker 2005). It further remains debated in the literature to what extent a gender effect exists for loss aversion, with existing studies finding effects in different directions (Schmidt and Traub 2002; Brooks and Zank 2005; Abdellaoui et al. 2008; Harrison and Rutström 2009; Booij et al. 2010; Gächter et al. 2010; Holden 2014; Andersson et al. 2016a).

There is currently no agreement on the correct definition of loss aversion (Schmidt and Zank 2005). We illustrate how even subtle differences in the definition of loss aversion may result in the estimation of contradictory gender effects. Using four definitions of loss aversion commonly used in the literature, we show that according to one definition women are more loss averse than men, whereas according to another there is no gender effect; using the remaining two, we find women to be less loss averse than men. These radically different conclusions are all the more remarkable since they are obtained i) based on the same data; ii) based on the same functional forms and econometric setup; and iii) using definitions that are commonly employed in the literature, and the subtleties of which can easily escape scrutiny when presented in isolation. It should thus be clear that the four definitions we present serve only illustrative purposes, and that additional variation could result from changes in some of the elements we hold constant across our definitions.

We further show that the differences in the inferences we report originate from the derivation of loss aversion from the combination of parameters estimated over pure gains and over pure losses, and from the use we make of them to identify loss aversion from decisions in mixed gain-loss tasks. Since we observe gender differences in risk preferences over pure gains, different ways of capturing risk aversion over gains across the different models can result in radically different conclusions about loss aversion. Ultimately, one's interpretation of gender effects will thus crucially depend on what one considers the 'correct' interpretation of loss aversion-an issue on which scholars disagree. The discordant findings can be conceptually organized by measurement error, which in this case may result from modelling assumptions.

\section{Definitions of loss aversion}

\subsection{General setup}

We model preferences over binary prospects $\xi=(x, 0.5 ; y)$, where the outcome $x$ obtains with a probability 0.5 , or else $y$. Outcomes are modelled as changes in asset positions relative to a status quo of zero. This status quo is induced in our experimental design based on certainty equivalents $(C E s)$, which serve to avoid endogenous 
reference points since they compare an invariant prospect or lottery to changing sure amounts that always fall between the outcomes of the prospect (Hershey and Schoemaker 1985). In the mixed outcome domain, a prospect over a fixed gain and a varying loss amount is compared to a fixed outcome of 0 , which again serves to fix the reference point to zero (Tversky and Kahneman 1992).

We model outcomes as being subjectively transformed into utilities via a monotonically increasing utility function, $u$. Probabilities are subjectively transformed into domain-specific decisions weights $\pi^{s} \equiv w^{s}(0.5)$, where $s$ indicates the sign (gains or losses), and $w:[01] \rightarrow[01]$ is a function mapping probabilities into decision weights, with $w^{s}(0)=0$ and $w^{s}(1)=1$. Estimating a single decision weight instead of a full probability weighting function has the advantage that we do not need to make any assumptions about the functional form of the probability weighting function (Abdellaoui et al. 2008). For pure gains or losses the utility of a prospect takes the following form:

$$
U(\xi)=\pi^{s} u(x)+\left(1-\pi^{s}\right) u(y) .
$$

For mixed prospects, the utility of a prospect can be represented as:

$$
U(\xi)=\pi^{+} u(x)+\pi^{-} u(\ell),
$$

where $\ell$ represents the loss amount, and $\pi^{-}=w^{-}(0.5)$. This equation follows from gain-loss separability, a principle whereby behaviour in the mixed outcome domain can be modelled as an additive composition of the two parts taking place over pure gains and over pure losses (Wakker 2010).

The utility function, $u$, takes the form of a reference-dependent function with a kink at the fixed reference point of $u(0)=0$ :

$$
u(x)=\left\{\begin{array}{cc}
v(x) & \text { if } x>0 \\
-\lambda v(-x) & \text { if } x \leq 0,
\end{array}\right.
$$

where $v$ is a value function defined over outcomes in the pure outcome domains. We specify this function using an exponential utility function. This functional form avoids issues of scaling encountered when using domain-specific power utility in the estimation of loss aversion parameters (Wakker 2010, section 9.6), which may otherwise distort the estimated coefficient of loss aversion. ${ }^{1}$ Our results are stable to the use of alternative functional forms. This function takes the following form:

$$
v(x)=\left\{\begin{aligned}
\frac{1-\mathrm{e}^{-\mu x}}{\mu} & \text { if } x>0 \\
\frac{1-\mathrm{e}^{-v(-x)}}{v} & \text { if } x \leq 0,
\end{aligned}\right.
$$

\footnotetext{
${ }^{1}$ For instance, the estimated loss aversion parameter may depend on the currency in which outcomes are denominated when adopting power utility with different parameters for gains and losses. For instance, adopting the OPT definition discussed below, we estimate $\lambda=2.36$ when all outcomes are divided by the highest prize to rescale them to the unit interval, but $\lambda=1.01$ and not significantly different from 1 when all outcomes are denominated in Euros. When all outcomes are denominated in Thai Bhat (Euros times 20 in purchasing power parity), we obtain $\lambda=0.48$, and significantly smaller than 1 . Loss aversion can thus be rescaled at will under this functional assumption - an element that is clearly undesirable.
} 
where $\mu$ determines utility curvature for gains, with $\mu \geq 0$ indicating concavity and $\mu \leq 0$ convexity of the utility function; and $v$ determines curvature for losses, with $v \geq 0$ indicating convexity and $v \leq 0$ concavity. The value function $v$ and decision weights $\pi^{s}$ are identified from Eq. 1 using pure gain and pure loss prospects. Equation 2 then identifies loss aversion, with $\lambda$ the only parameter remaining to be assessed.

\subsection{Definitions of loss aversion}

We estimate the loss aversion coefficient from structural equations using state-of-theart econometric procedures - see the Appendix for details. To identify loss aversion, we use choices between a sure outcome of 0 (not playing) and a prospect involving a given gain $x$ and different losses $\ell$. Substituting (3) into (2), setting $v(0)=0$, and solving the equation thus obtained for the loss aversion parameter, $\lambda$, we obtain:

$$
\lambda=\frac{\pi^{+}}{\pi^{-}} \frac{v(x)}{v(\ell)} .
$$

The loss aversion coefficient is thus identified by a ratio of the decision weights, multiplied by a ratio of utilities (Schmidt and Zank 2005). From this general equation, we derive the following four definitions:

1. Cumulative Prospect Theory $(C P T)$. This is the definition as presented in Eq. 5 . Decision weights are allowed to differ for gains and losses in the model, i.e. in principle $\pi^{+} \neq \pi^{-}$, and hence will form integral part of the definition of the loss aversion parameter (Schmidt and Zank 2005; Zank 2010). Because this definition naturally arises out of the CPT model, this is amongst the most commonly implemented definitions in structural estimations of prospect theory (Harrison and Rutström 2009; Booij et al. 2010; L'Haridon and Vieider 2019).

2. Original Prospect Theory $(O P T)$. A drawback of the CPT definition is that the inclusion of decision weights introduces differences between loss aversion under risk and under certainty (Kahneman et al. 1991; Gächter et al. 2010). Under OPT (Kahneman and Tversky 1979), decision weights play no role in the definition of loss aversion (Schmidt and Zank 2005). The definition thus simplifies to $\lambda_{\mathrm{OPT}}=$ $v(x) / v(\ell)$, where decision weights drop out since under OPT $\pi^{+}=\pi^{-2}$

3. Markowitz-Expected Utility $(M E U)$. Although loss aversion is now seen as an integral part of prospect theory, it was already discussed and modeled by Markowitz (1952). Since probabilities are treated linearly in Markowitz's model, utility curvature will generally not be the same as under prospect theory

\footnotetext{
${ }^{2}$ In practice, this assumption is often adopted because of data restrictions. The equality of decision weights for 50-50 mixed prospects is, however, not the only way of obtaining this definition. For instance the same definition may obtain because-even though decision weights are allowed to differ between gains and losses-subjects edit out the symmetric probability in mixed decisions because of the increased salience of the outcomes relative to probabilities in such decisions (Tversky 1972). This definition is also typically used in non-parametric elicitations of loss aversion (Abdellaoui et al. 2007), where the decision weights drop out by design of the elicitation procedure. The estimated parameters under these different techniques may once again differ from the ones obtained here.
} 
(Abdellaoui et al. 2007; Booij et al. 2010). The loss aversion parameter now is $\lambda_{\mathrm{MEU}}=\tilde{v}(x) / \tilde{v}(\ell)$, where the 'tilde' serves to remind us that the utility function is not generally the same as the one seen above. This family of models has recently been used e.g. by von Gaudecker et al. (2011) and Andersson et al. (2016a).

4. Gain-Loss Ratio $(G L R)$. This definition obtains from Eq. 5 by setting $\pi^{+}=p$, $\pi^{-}=1-p$ and $v(z)=z$. For the case of $p=1-p$, we thus obtain $\lambda_{G L R}=$ $x / \ell$. The GLR is often referred to as 'behavioural loss aversion', although we find that term misleading, since it is not a true measure of loss aversion, but rather a measure of risk aversion over mixed gain-loss prospects. Arguably, this definition is the most commonly used in the literature owing to its simplicity (e.g. Tom et al. 2007; Gächter et al. 2010; Martino et al. 2010).

The list of definitions provided above is not meant to be exhaustive, and additional definitions could result from either psychological theory or changes of functional forms (e.g., different utility specifications, or restrictions forcing the utility parameter for gains and losses to be the same). This is of little concern here, since we intend to use these definitions merely for illustrative purposes of what may happen to regression analysis under different definitions of loss aversion.

\section{Experimental design}

We use data for close to 3000 students across 30 countries presented by Vieider et al. (2015). The dataset contains responses from a total of 2939 students across 30 countries, obtained in identical experiments. We elicited certainty equivalents (CEs) for a total of 44 binary prospects. We exclude 16 of those prospects which capture ambiguity attitudes, and which are analyzed in L'Haridon et al. (2018). We further restrict our attention to prospects offering 50-50 probabilities, which are sufficient to identify the decision weights in our model, doing away with the necessity of estimating full probability weighting functions (Abdellaoui et al. 2008). The tasks included in our analysis are shown in Table 1 , with prospects indicated in the form $(x, y)$, given that probabilities are always 50-50. Losses were implemented from an endowment equal

Table 1 Experimental tasks

\begin{tabular}{lll}
\hline Gains & Losses & Mixed \\
\hline$(5,0)$ & $(-5,0)$ & $(20,-\ell)$ \\
$(10,0)$ & $(-10,0)$ & \\
$(20,0)$ & $(-20,0)$ & \\
$(30,0)$ & $(-20,-5)$ & \\
$(30,10)$ & $(-20,-10)$ & \\
$(30,20)$ & & \\
\hline
\end{tabular}

Amounts refer to PPP Euros; $€ 1=\$ 1.2$ PPP 
to the largest possible loss, and given to subjects conditional on playing out a lottery involving losses. Tasks over pure gains and pure losses involved choices between a lottery and sure amounts that ranged from the lowest to the highest amount in the prospect. For the mixed prospect we elicited the loss amount $\ell$ that made a decision maker indifferent between the prospect and the status quo of zero.

The mixed prospect is displayed in Fig. 1. Subjects were asked to decide between the status quo and a lottery offering a gain of $€ 20$ or else a sequence of losses

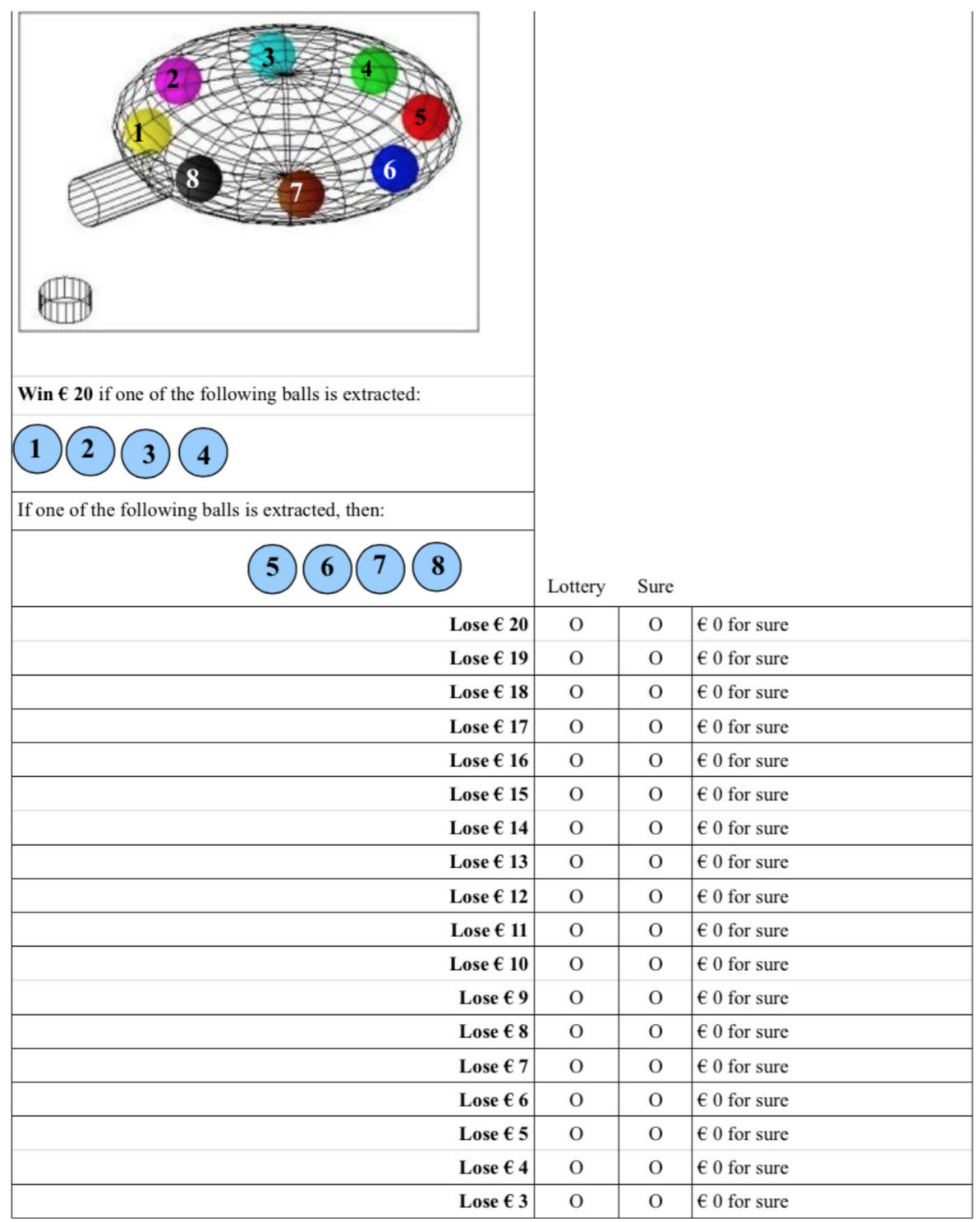

Fig. 1 Elicitation of loss equivalent 
ranging from $€ 20$ to $€ 3$. The point where a subject switched from preferring the status quo to preferring the prospect was encoded as the loss equivalent $\ell$. We approximate the exact amount by the mean between the last loss for which a subject preferred the status quo and the first for which a subject preferred the lottery. Multiple switching was excluded by design in order to avoid differing multiple switching proportions between countries, which would have made the analysis difficult.

At the conclusion of a session, either the gain or the loss part were randomly selected for real play. Then one of the tasks within the selected part was randomly selected and one of the decisions was played out. ${ }^{3}$

\section{Results}

We regress the coefficient of loss aversion estimated according to the different definitions on a female dummy. All regressions further include country fixed effects, with the missing dummy indicating preferences measured in the USA. The correlations shown are stable to inserting a host of additional demographic controls, as well as to substituting the country dummies with macro-economic variables such as GDP per capita.

Table 2 shows the results. According to the GLR definition, there is a significant gender effect, indicating that women are more loss averse than men. When we adopt the MEU or OPT definitions instead, however, this finding is exactly reversed. Women are now found to be significantly less loss averse than men. Adopting the fully general CPT definition, we do not detect any gender effect for loss aversion. Our conclusion on gender effects in loss aversion will thus strongly depend on the definition of loss aversion adopted. This is all the more remarkable since any of the definitions may appear quite natural when presented in isolation-indeed all of the definitions presented have been used in the literature.

Why such discordant effects? Risk preferences over pure gains and over pure losses will influence the definition of loss aversion according to the axiom of gain-loss separability underlying (2). This is easily illustrated using the average estimated parameters. Under the GLR definition, our loss aversion measure is simply $\lambda_{G L R}=x /-\ell$. Since $x$ is fixed at $€ 20$, we can see that $-\ell$ is $€ 11.36$ for men, and $€ 10.75$ for women. That is, the maximum acceptable loss for preferring the lottery over the status quo of 0 is smaller for women, indicating increased risk aversion.

Passing to the MEU definition, these ratios of values remain the same, but they are now transformed into utilities, so that $\lambda_{M E U}=v(x) / v(\ell)$. Given the estimated utility curvature parameters, the $€ 20$ gain has a utility of 16.18 for men, but only of 14.77 for women. Meanwhile, the mean loss amount for men of $€ 11.36$ receives a utility of 11.55 , while the loss of 10.75 for women receives a utility weight of 11.17 .

\footnotetext{
${ }^{3}$ The full instructions in several languages can be found online at https://figshare.com/s/ 5e655fa13f5ea76bdf99.
} 
Table 2 Regression of loss aversion on individual characteristics depending on definition

\begin{tabular}{|c|c|c|c|c|c|c|c|c|}
\hline & \multicolumn{2}{|l|}{ GLR } & \multicolumn{2}{|l|}{ MEU } & \multicolumn{2}{|l|}{ OPT } & \multicolumn{2}{|l|}{$\mathrm{CPT}$} \\
\hline & Female & Constant & Female & Constant & Female & Constant & Female & Constant \\
\hline$\lambda$ & $\begin{array}{l}0.100^{* * * *} \\
(0.032)\end{array}$ & $\begin{array}{l}1.761^{* * *} \\
(0.088)\end{array}$ & $\begin{array}{l}-0.110^{* *} \\
(0.049)\end{array}$ & $\begin{array}{l}1.421^{* * *} \\
(0.095)\end{array}$ & $\begin{array}{l}-0.108^{* *} \\
(0.045)\end{array}$ & $\begin{array}{l}1.393^{* * *} \\
(0.088)\end{array}$ & $\begin{array}{l}-0.053 \\
(0.041)\end{array}$ & $\begin{array}{l}1.324^{* * *} \\
(0.070)\end{array}$ \\
\hline$\mu$ & - & - & $\begin{array}{l}0.010^{* * *} \\
(0.002)\end{array}$ & $\begin{array}{l}0.022^{* * *} \\
(0.005)\end{array}$ & $\begin{array}{l}0.007^{* *} \\
(0.002)\end{array}$ & $\begin{array}{l}0.035^{\text {*** }} \\
(0.005)\end{array}$ & $\begin{array}{l}0.004^{*} \\
(0.003)\end{array}$ & $\begin{array}{l}0.041 \\
(0.005)\end{array}$ \\
\hline$v$ & - & - & $\begin{array}{l}-0.004 \\
(0.003)\end{array}$ & $\begin{array}{l}-0.003 \\
(0.006)\end{array}$ & $\begin{array}{l}-0.010^{* *} \\
(0.004)\end{array}$ & $\begin{array}{l}0.016^{* *} \\
(0.008)\end{array}$ & $\begin{array}{l}-0.001 \\
(0.002)\end{array}$ & $\begin{array}{l}0.005 \\
(0.008)\end{array}$ \\
\hline$\pi^{+}$ & - & - & - & - & $\begin{array}{l}-0.009^{*} \\
(0.005)\end{array}$ & $\begin{array}{l}0.534^{* * *} \\
(0.010)\end{array}$ & $\begin{array}{l}-0.016^{* *} \\
(0.007)\end{array}$ & $\begin{array}{l}0.545^{* * *} \\
(0.015)\end{array}$ \\
\hline$\pi^{-}$ & - & - & - & - & $\begin{array}{l}-0.009^{*} \\
(0.005)\end{array}$ & $\begin{array}{l}0.534^{* * *} \\
(0.010)\end{array}$ & $\begin{array}{l}0.006 \\
(0.008)\end{array}$ & $\begin{array}{l}0.514^{* * *} \\
(0.016)\end{array}$ \\
\hline$\sigma$ & - & - & $\begin{array}{l}0.009^{* *} \\
(0.003)\end{array}$ & $\begin{array}{l}0.171^{* * *} \\
(0.008)\end{array}$ & $\begin{array}{l}0.009^{* *} \\
(0.003)\end{array}$ & $\begin{array}{l}0.170^{* * *} \\
(0.007)\end{array}$ & $\begin{array}{l}0.009^{* * *} \\
(0.003)\end{array}$ & $\begin{array}{l}0.171^{* * *} \\
(0.007)\end{array}$ \\
\hline
\end{tabular}

Standard errors in parentheses. $*$, **, $* * *$ indicate significance at the $10 \%, 5 \%$, and $1 \%$ level respectively. All regressions include country dummies

Relative to the GLR definition, we can thus see that, while there is little movement in the denominator, the numerator decreases substantially for women relative to men. This movement works towards a reduction in the utility ratio $v(x) / v(\ell)$ that is much stronger for women than for men, explaining the reversal in the estimated gender effect. For the other definitions the issue is similar, albeit a little more complex. In particular for the CPT definition, much of the gender differences for gains are captured by the decision weight rather than by utility curvature. This, in turn, reduces the impact of risk aversion for gains on the loss aversion parameter, resulting in a null finding.

All of this raises the question of which one is the 'correct' definition of loss aversion. Unfortunately, there is no simple answer to this question. The correct definition or model could well be subject-specific (Bruhin et al. 2010), posing non-trivial issues for estimations of the sort presented here. Even more generally, the validity of the principle of gain-loss separability underlying the equation used to identify loss aversion may be questionable from an empirical point of view (Baltussen et al. 2006; Wu and Markle 2008). If that principle fails in our data, then none of the definitions used may be correct, and specific models or identification procedures would need to be developed that can account for such violations and accurately model decisions over gain-loss prospects. It is tempting to conclude from all this that one ought to simply use a non-parametric measure such as the GLR. That measure is indeed a useful metric of risk preferences over mixed gain-loss prospects. It is, however, not a measure 
of loss aversion, so that it may also suffer from systematic distortions when used as a proxy for the latter. Although we find women to be clearly more risk averse over mixed prospect than men, the question of whether women are truly more loss averse than men thus remains unanswered at this point.

\section{Conclusion}

Gender effects in risk aversion are a much-debated topic in economics. Loss aversion-the stylized finding that losses weigh more heavily than gains in decision processes - is thought to constitute a fundamental psychological driver of risk aversion. However, loss aversion has been defined in many different ways, and there is no agreement about what the correct definition may be. Using four definitions commonly employed in the literature, we showed that they can result in very different conclusions on gender effects - no effect, women being more loss averse than men, or women being less loss averse than men. This finding is remarkable since all the definitions may appear natural if presented in isolation. It goes to show how even subtle modelling assumptions can yield different results in regression analysis, and thus presents a note of caution against the over-interpretation of any one analysis of a specific dataset.

The insights we presented raise the question of whether an accurate measurement of loss aversion can be obtained at all. The answer to that question will crucially depend on one's benchmark for accuracy. From a theoretical point of view, one may decide to argue for a given definition as the the 'correct' one, and then estimate that definition nonparametrically using tasks specifically devised to that end (see e.g. Abdellaoui et al. 2007, 2016). Such theory-driven approaches, however, are challenged by findings suggesting that one of the very principles underlying the identification of loss aversion, gain-loss separability, may be violated in practice (Wu and Markle 2008).

One can also approach the issue from an empirical standpoint. Given suitably rich data that allow for the identification of different assumptions about the definitions and functional forms (if any) to be deployed, it ought to be possible to identify the definition that best fits the observed behaviour at the individual level. One can then accept the parameter estimate emerging from the best-fitting definition as the correct one. Such an approach immediately suggests that restrictions to the model that are purely driven by insufficient data availability are unlikely to be optimal. Rather, one ought to move from the model — or rather a set of models and definitions - to the data collection if one hopes to implement such a procedure.

Even then, selecting the 'best' parameter based on the empirical data would be no simple feat. Individuals are likely to be heterogeneous in terms of the definition best fitting their choice pattern, the functional forms used for utility over gains and losses, the stochastic process by which decisions are reached, and the extent to which they obey gain-loss separability. Suitably identifying all these elements will require extremely rich data, as well as heavy-handed econometrics. In practical applications, researchers will thus still need to make choices based on their prior of which elements may be of primary importance, and which may not. 
From a conceptual point of view, the contradictory results we obtained can be thought of as an instance of measurement error resulting from model misspecification relative to the true underlying decision process. The contradictory regression results can then be explained by systematic errors in the estimation of the loss aversion parameter that are correlated with one or more of the explanatory variables, thus leading to systematic bias in regression analysis (see e.g. Wooldridge 2015, section 9-4a). Such model mis-specifications are likely to be much more common than one may think, and are not specific to the mixed outcome domain. This is because assumptions about and restrictions to parametric estimations are common, either because of data restrictions, oversight, or individual heterogeneity in the correct decision model or functional form.

Nor are such errors confined to structural models of decision making. For instance, Crosetto and Filippin (2015) showed that estimated risk preferences may systematically differ by measurement tasks. Such differences can once again be conceptualized as systematic measurement errors, and thus induce bias in regression analysis. Using choice lists cut off at different points, Andersson et al. (2016b) showed that regression analysis could return a positive or a negative effect of cognitive ability on estimated risk aversion, depending on which of the lists was used.

Ultimately, we thus see the results presented in this paper as a call for a more systematic exploration of the consequences of measurement and modelling error on statistical inferences for preference parameters. Measures of risk preferences are well known to be noisy, and subject to contextual influences pertaining to the measurement task, the presentation of stimuli, etc. Nor is measurement error confined to preferences alone, with many correlates investigated in the literature likely subject to systematic error as well. Obtaining a better understanding of the direction of such measurement errors and how they may impact empirically measured correlations-be they between different measures of risk preferences or between risk preference measures and behaviour or dempgraphic characteristics-will thus be crucial for a consolidation of this literature.

Acknowledgments Ferdinand Vieider gratefully acknowledges generous financial support from the Excellence Initiative at the University of Munich and from the WZB Berlin Social Science Center.

Open Access This article is distributed under the terms of the Creative Commons Attribution 4.0 International License (http://creativecommons.org/licenses/by/4.0/), which permits unrestricted use, distribution, and reproduction in any medium, provided you give appropriate credit to the original author(s) and the source, provide a link to the Creative Commons license, and indicate if changes were made.

\section{Appendix: Econometric approach}

Our econometric approach relies on directly estimating the density around the switching point, following Bruhin et al. (2010). For a given prospect involving pure gains or pure losses, we can represent the modelled equivalent, $\hat{z}_{i}$, as follows:

$$
\hat{z}_{i}=u^{-1}\left[\pi^{s} u\left(x_{i}\right)+\left(1-\pi^{s}\right) u\left(y_{i}\right)\right],
$$


where the power -1 designates the inverse of a function. For mixed prospects involving gains and losses, we can define the modelled equivalent loss, which we again designate by $\hat{z}_{i}$, that makes the decision maker indifferent between the prospect and the status quo:

$$
\hat{z_{i}}=v^{-1}\left[\frac{\pi^{+} v\left(x_{i}\right)}{\lambda \pi^{-}}\right] .
$$

The modelled equivalents in the two preceding equations depend on the estimated preference parameters $\left\{\mu, v, \lambda, \pi^{+}, \pi^{-}\right\}$. The difference in the identifying equation is driven by the difference in elicitation methods for mixed prospects and for gains and losses.

We now introduce an explicit stochastic structure. The observed equivalent, $z_{i}$ (which could be either a certainty equivalent, $c e_{i}$, or a loss equivalent, $\ell_{i}$ ), will be equal to the equivalent calculated from our model plus some independently distributed error term, or $z_{i}=\hat{z}_{i}+\epsilon_{i}$. Errors may be generated in utility calculation, mistakes in recording the answers, or from the mis-specification of the model relative to the true underlying decision process generating the data (Train 2009). We assume this error to be normally distributed, $\epsilon_{i} \sim \mathcal{N}\left(0, \sigma_{i}^{2}\right)$. The parameter $\sigma_{i}$ indicates the standard deviation of a so-called Fechner error (Hey and Orme 1994). We allow for three different types of heteroscedasticity. Firstly, the error is allowed to differ between gains and losses. For mixed prospects, we adopt the error for losses, since it is the loss amount that varies in the mixed choice lists. Secondly, we allow the error term to depend on the specific prospect, or rather, on the difference between the high and low outcome in the prospect, such that $\sigma_{s i}=\sigma_{s}\left|x_{i}-y_{i}\right|$. For the mixed prospects, the error term depends on the maximum range in the loss domain. This takes into account that the error may be related to the length of the choice list, which will vary with the difference between the two outcomes of the prospect given fixed steps between the sure amounts. Finally, we let the error term $\sigma$ depend linearly on the characteristics of the decision maker, $n$, so that $\sigma_{s}=\sigma_{0}+X_{n} \eta$, with $\eta$ a vector of regression parameters.

We can express the probability density function $\psi($.) for a given subject $n$ and prospect $\xi_{i}$ as follows

$$
\psi\left(\theta_{n}, \xi_{i}\right)=\phi\left(\frac{\hat{z}_{n i}\left(\mu_{n}, v_{n}, \lambda_{n}, \pi_{n}^{+}, \pi_{n}^{-}\right)-z_{n i}}{\sigma_{n i s}}\right)
$$

where $\phi$ is the standard normal density function, and $\theta_{n}=\left\{\mu_{n}, v_{n}, \lambda_{n}, \pi_{n}^{+}, \pi_{n}^{-}, \sigma_{n}\right\}$ indicates the vector of model parameters. Taking logs and summing over individuals and prospects, we obtain the following aggregate log-likelihood function:

$$
L L(\theta)=\sum_{n=1}^{N} \sum_{i=1}^{I} \log \left[\psi\left(\theta_{n}, \xi_{i}\right)\right] .
$$

Within this grand likelihood, we let the vector of parameters depend linearly on the observable characteristics of decision makers, such that $\theta_{n}=\theta_{k}+X_{n} \gamma$, where $\theta_{k}$ is a k-dimensional vector of constants corresponding to the number of parameters in our model, $X_{n}$ represents an $n \times m$ matrix of observable characteristics of the decision makers, and $\gamma$ is a $m \times k$ matrix of regression coefficients, where $k$ indicates 
the number of parameters, and $m$ the number of predictors. We always cluster errors at the subject level.

\section{References}

Abdellaoui, M., Bleichrodt, H., Paraschiv, C. (2007). Loss aversion under prospect theory: A parameterfree measurement. Management Science, 53(10), 1659-1674.

Abdellaoui, M., Bleichrodt, H., L'Haridon, O. (2008). A tractable method to measure utility and loss aversion under prospect theory. Journal of Risk and Uncertainty, 36(3), 245-266.

Abdellaoui, M., Bleichrodt, H., L'Haridon, O., Van Dolder, D. (2016). Measuring loss aversion under ambiguity: A method to make prospect theory completely observable. Journal of Risk and Uncertainty, 52(1), 1-20.

Andersson, O., Holm, H.J., Tyran, J.-R., Wengström, E. (2016a). Deciding for others reduces loss aversion. Management Science, 61(1), 29-36.

Andersson, O., Tyran, J.-R., Wengström, E., Holm, H.J. (2016b). Risk aversion relates to cognitive ability: Preferences or noise? Journal of the European Economic Association, 14(5), 1129-1154.

Balafoutas, L., \& Sutter, M. (2012). Affirmative action policies promote women and do not harm efficiency in the laboratory. Science, 335(6068), 579-582.

Baltussen, G., Post, T., van Vliet, P. (2006). Violations of cumulative prospect theory in mixed gambles with moderate probabilities. Management Science, 52(8), 1288-1290.

Benartzi, S., \& Thaler, R.H. (1995). Myopic loss aversion and the equity premium puzzle. The Quarterly Journal of Economics, 110(1), 73-92.

Booij, A.S., van Praag, B.M.S., van de Kuilen, G. (2010). A parametric analysis of prospect theory's functionals for the general population. Theory and Decision, 68(1-2), 115-148.

Brooks, P., \& Zank, H. (2005). Loss averse behavior. Journal of Risk and Uncertainty, 31(3), 301-325.

Bruhin, A., Fehr-Duda, H., Epper, T. (2010). Risk and rationality: Uncovering heterogeneity in probability distortion. Econometrica, 78(4), 1375-1412.

Crosetto, P., \& Filippin, A. (2015). A theoretical and experimental appraisal of four risk elicitation methods. Experimental Economics, 1-29.

Croson, R., \& Gneezy, U. (2009). Gender differences in preferences. Journal of Economic Literature, 47(2), 1-27.

Dwyer, P.D., Gilkeson, J.H., List, J.A. (2002). Gender differences in revealed risk taking: Evidence from mutual fund investors. Economics Letters, 76(2), 151-158.

Filippin, A., \& Crosetto, P. (2016). A reconsideration of gender differences in risk attitudes. Management Science, 62(11), 3138-3160.

Gächter, S., Johnson, E.J., Herrmann, A. (2010). Individual-level loss aversion in riskless and risky choices. Technical Report 2010-20, CeDEx discussion paper series.

Gneezy, U., \& Potters, J. (1997). An experiment on risk taking and evaluation periods. The Quarterly Journal of Economics, 112(2), 631-45.

Harrison, G.W., \& Rutström, E. (2009). Expected utility theory and prospect theory: One wedding and a decent funeral. Experimental Economics, 12(2), 133-158.

Hershey, J.C., \& Schoemaker, P.J.H. (1985). Probability versus certainty equivalence methods in utility measurement: Are they equivalent? Management Science, 31(10), 1213-1231.

Hey, J.D., \& Orme, C. (1994). Investigating generalizations of expected utility theory using experimental data. Econometrica, 62(6), 1291-1326.

Holden, S.T. (2014). Risky choices of poor people: Comparing risk preference elicitation approaches in field experiments. CLTS Working Paper.

Kahneman, D., \& Tversky, A. (1979). Prospect theory: An analysis of decision under risk. Econometrica, 47(2), 263-291.

Kahneman, D., Knetsch, J.L., Thaler, R.H. (1991). Anomalies: The endowment effect, loss aversion, and status quo bias. Journal of Economic Perspectives, 5(1), 193-206.

Köbberling, V., \& Wakker, P.P. (2005). An index of loss aversion. Journal of Economic Theory, 122(1), 119-131.

L'Haridon, O., \& Vieider, F.M. (2019). All over the map: A worldwide comparison of risk preferences. Quantitative Economics, 10, 185-215. 
L'Haridon, O., Vieider, F.M., Aycinena, D., Bandur, A., Belianin, A., Cingl, L., Kothiyal, A., Martinsson, P. (2018). Off the charts: Massive unexplained heterogeneity in a global study of ambiguity attitudes. Review of Economics and Statistics, 100(4), 664-677.

Markowitz, H. (1952). The utility of wealth. Journal of Political Economy, 60(2), 151-158.

Martino, B.D., Camerer, C.F., Adolphs, R. (2010). Amygdala damage eliminates monetary loss aversion. Proceedings of the National Academy of Sciences, 107(8), 3788-3792.

Niederle, M., \& Vesterlund, L. (2005). Do women shy away from competition? Do men compete too much? Working Paper 11474. National Bureau of Economic Research.

Rabin, M., \& Thaler, R.H. (2001). Anomalies: Risk aversion. The Journal of Economic Perspectives, 15(1), 219-232.

Schmidt, U. (2003). Reference dependence in cumulative prospect theory. Journal of Mathematical Psychology, 47(2), 122-131.

Schmidt, U., \& Traub, S. (2002). An experimental test of loss aversion. Journal of Risk and Uncertainty, 25(3), 233-249.

Schmidt, U., \& Zank, H. (2005). What is loss aversion? Journal of Risk and Uncertainty, 30(2), 157-167.

Sunden, A.E., \& Surette, B.J. (1998). Gender differences in the allocation of assets in retirement savings plans. The American Economic Review, 88(2), 207-211.

Tom, S.M., Fox, C.R., Trepel, C., Poldrack, R.A. (2007). The neural basis of loss aversion in decisionmaking under risk. Science, 315(5811), 515-518.

Train, K. (2009). Discrete choice methods with simulation. Cambridge: Cambridge University Press.

Tversky, A. (1972). Elimination by aspects: A theory of choice. Psychological Review, 79(4), 281-299.

Tversky, A., \& Kahneman, D. (1992). Advances in prospect theory: Cumulative representation of uncertainty. Journal of Risk and Uncertainty, 5, 297-323.

Vieider, F.M., Lefebvre, M., Bouchouicha, R., Chmura, T., Hakimov, R., Krawczyk, M., Martinsson, P. (2015). Common components of risk and uncertainty attitudes across contexts and domains: Evidence from 30 countries. Journal of the European Economic Association, 13(3), 421-452.

von Gaudecker, H.-M., van Soest, A., Wengström, E. (2011). Heterogeneity in risky choice behaviour in a broad population. American Economic Review, 101(2), 664-694.

Wakker, P.P. (2010). Prospect theory for risk and ambiguity. Cambridge: Cambridge University Press.

Wooldridge, J.M. (2015). Introductory econometrics: A modern approach. Nelson Education.

Wu, G., \& Markle, A.B. (2008). An empirical test of gain-loss separability in prospect theory. Management Science, 54(7), 1322-1335.

Zank, H. (2010). On probabilities and loss aversion. Theory and Decision, 68(3), 243-261.

Publisher's note Springer Nature remains neutral with regard to jurisdictional claims in published maps and institutional affiliations. 


\section{Affiliations}

Ranoua Bouchouicha ${ }^{1}$ - Lachlan Deer ${ }^{2}$. Ashraf Galal Eid ${ }^{3}$. Peter McGee . $^{4}$ Daniel Schoch ${ }^{5} \cdot$ Hrvoje Stojic $^{6}$ • Jolanda Ygosse-Battisti ${ }^{7}$. Ferdinand M. Vieider ${ }^{8}$

Lachlan Deer

lachlan.deer@econ.uzh.ch

Ashraf Galal Eid

ashraf.eid@qu.edu.qa

Peter McGee

pmcgee@walton.uark.edu

Daniel Schoch

Daniel.Schoch@nottingham.edu.my

Hrvoje Stojic

hrvoje.stojic@protonmail.com

Jolanda Ygosse-Battisti

jolanda.ygosse@fgv.br

Ferdinand M. Vieider

ferdinand.vieider@ugent.be

1 Henley Business School, University of Reading, Reading, UK

2 University of Zurich, Zurich, Switzerland

3 Finance and Economics Department, Qatar University, Doha, Qatar

4 University of Arkansas, Fayetteville, AR, USA

5 University of Nottingham Malaysia Campus, Semenyih, Malaysia

6 Universitat Pompeu Fabra, Barcelona, Spain

7 São Paolo School of Business, São Paolo, Brazil

8 Department of Economics, Ghent University, Ghent, Belgium 